\title{
Effect of Fun Learning Enrichment Program (FLEP) on At-Risk Students' Motivation and Aspiration to Learn
}

\author{
Noriah Mohd Ishak ${ }^{1}$, Melor Md Yunos², Salleh Amat ${ }^{3}$, Abu Yazid Abu Bakar ${ }^{4}$, \\ Mhd Subhan ${ }^{5}$ \\ ${ }^{1,2,3,4}$ Universiti Kebangsaan Malaysia \\ ${ }^{5}$ Universitas Islam Negeri Sultan Syarif Kasim Riau \\ e-mail: noriah@gmail.com
}

\begin{abstract}
ABSTRAK. The purpose of this study is to examine effects of the Fun Learning Enrichment Program (FLEP) on motivation and aspiration to learn among population of low-achieving students. The study used quasi experimental design with pre-post control group. A total of 596 students participated in the study for three consecutive years. The students were given a module consisted of 120 fun learning enrichment activities in mathematics and science that promotes selfmotivation and aspiration to learn. Results show significant increase in motivation and aspiration to learn among the students after attending the FLEP program. In conclusion, low-achieving students can develop motivation and aspiration to learn when given environment that promotes positive learning experience.
\end{abstract}

Kata kunci: Learning; low-achieving students; motivation; enrichment program.

\section{INTRODUCTION}

People are basically constructive and trustworthy. When they are free from defensiveness that creates maladjustment, their reactions are positive and forward-looking. Concomitantly, Rogers (1980) suggested that each of us have the capacity and the tendency to move away from any state of maladjustment towards a state of psychological adjustment. When these individuals are provided with reasonable growth, their potential will develop constructively, like seeds that grow into a shady tree. The tendency towards adjustment is according to Rogers, the tendency toward self-actualization. Rogers (1980) suggested that human beings are capable of solving their own problems, know what they want in life and work towards that direction. Hence, they are viewed as proactive rather than reactive (Pajares, 2003). They are not controlled by biological or environmental forces and, can self-regulate their own learning behaviors. These are positive selfbeliefs that allow them to apply a degree of control over their thoughts, feelings and actions. Learning motivation and aspiration to learn are examples of psychological elements triggered from positive self-beliefs.

A large body of research has demonstrated the pivotal role of learning motivation (Schicka \& Phillipson, 2009; Lau \&, Chan, 2001; Elliot et al., 2001; DeBacker \& Nelson, 1999; Alderman, 1990; Pintrich \& De Groot, 1990), and aspiration to learn (Secretan, 2005, Tan, et al., 2007), in different domains of human functioning. Pintrich (1989) suggested that there are three motivational components related to students' learning behaviors; (a) an expectancy component (students' beliefs about their ability to perform a task, (b) a value component, (students' goals and beliefs about the importance of the task, and (c) an affective component (students' emotional reactions to the task). A study conducted by Pintrich and De Groot (1990) and Pajares (2003) show that highly motivated students perform better than their peers who have low motivation. 
These students have the ability to self-regulate their own learning process as compared to their low motivated peers. A study conducted by Schicka and Phillipson (2009) shows that learning motivation is independent of general intelligence but relates to personal character such as aspiration to learn. As such, regardless of level of intelligence, students can be motivated to learn and, therefore, improve their academic performance.

With respect to gender differences, studies have shown that learning motivation depends on how the academic domain in question is perceived by the male and female students (Eisenberg et. al., 1996; Pajares \& Graham, 1999; Pajares \& Valiante, 2001). Numerous studies have also shown that girls are more motivated to learn social science subjects, while boys are more motivated to learn subjects related to mathematics and science (Pajares et al., 1999; Pajares et al., 2000; Pajares \& Valiante, 2001). Frank (1935) suggested that the relationship between the level of aspiration and the level of past performance depends upon "the relative strengths of the need to keep the level of aspiration high, the need to make the level of aspiration approximate the level of performance as closely as possible, and the need to avoid failure" (p. 127). Frank then insinuated that when one sets a goal, it is usually somewhere between the individual's assessment of their ability and their motivation to achieve the best performance possible. When the subject either experienced success on a previous assignment or anticipated or aspire to be successful in a future task, they will experience higher motivation (Gebhard, 1948). Hitherto, there are plenty of evidence to suggest that there is a linear relationship between motivation and aspiration to learn; the higher the aspiration the higher the motivation to learn. Pajares and Valiante (2001) and Henal Shah (2007) posited that children psychological state of mind influenced their ability to withstand the rigorousness of their learning curve. Children, who have high aspiration to learn, for example, will develop intrinsic motivation towards learning and, therefore, will be more creative in developing their thinking skills for learning. Subsequently, they will be seen as more successful in academic work as compared to children who do not exhibit such characteristics. Needless to say, these students need to learn to tie their success and failures to their own efforts.

Children with learning disabilities or low-achieving students will be motivated to learn when given the appropriate instructions and effective learning strategy (Maheady et. al., 2000; Cheung \& Chang, 2008; Harper \& Maheady, 2007). Research have shown that such students will not benefit from the normal chalk and talk, lecture methods or teacher-centered teaching, but will response positively towards student-centered leaning (Hargis, 2006; Ganci et al., 2009; Wong et al., 1996). When teaching is properly facilitated, it allows effective learning engagement between students, peers and their teachers (Brophy \& Good, 1988). This can encourage collaborative learning efforts among those involved (Kagan, 1992). On a different note, Cheung and Chang (2008) suggested that there should be continuity between the formal and informal learning process that happened in schools and at home. Parents who encourage their children to learn will develop children who are highly motivated with their own learning process and become intrinsically motivated to explore knowledge on their own.

In Malaysia, students' academic achievement is a significant concern of most parents, teachers and school administrators, especially for those who are involved with educating the lowachieving or "at risk" students whose numbers are on the rise. Research by National Union of Teachers and Parents Association (NUTP) in 2005 showed that 10,000 students from primary school in Malaysia were unable to read well. Many were not capable of completing whole school years and faced with academic failure because of illiteracy. This is also reported by local newspapers, which stated that in 2006 about 120,000 primary school children or 2.2 percent of 3.1 million students were unable to read and write, and hence did poorly in schools. If intervention is not introduced to help improved the low-achievers' academic performance, the projected number by 2010 will reach half a million. Perkins-Gough (2006) suggested that to help such students; they have to be identified early and academic intervention has to be introduced immediately. Kajamies, et al. (2010), indicated that such intervention should be combined with intensive, systematic, and 
explicit teacher scaffolding within the cognitive, affective, and motivational activities that involve skillful problem solving. Consequently, the current research examined the effects of an intervention called Fun Learning Enrichment Program (FLEP) on low-achievers' learning motivation and aspiration to learn over a period of three years. Students learning motivation and aspiration to learn was compared between the first, second and third year. Comparison on the effect of FLEP on learning motivation and aspiration to learn was also made between the male and female low-achievers.

\section{Fun Learning Enrichment Program (FLEP)}

Fun Learning Enrichment Program (FLEP) is part of a program under Program Bakti Pendidik PETRONAS (PBPP), a Corporate Social Responsibility (CSR) program that was organized by one of the Malaysian giant oil company with UKM. Its' objective is to enhance the quality of education among selected low-achieving students from 150 primary schools distributed all over Malaysia. The aim of the program was to build positive characters (motivation and aspiration to learn, self-confidence, communication ability and thinking skills) among primary school children to help boast their academic performance. It involves collaboration between parents, teachers and facilitators to motivate low-achieving students to perform well in their academic work. FLEP is an informal instructional learning program which encompassed 120 fun learning mathematics and science activities divided into three tiers according to the age group of the students (10, 11 and 12 years old). Each tier has four levels of thinking skills (Enquire skills, Information Processing Skills, Reasoning Skills and Evaluation Skills) embedded into the learning activities. Table 1 shows the thinking skills and the activities used to promote the motivation and aspiration to learn among the students duri.

Table 1. FLEP Thinking Skills and Examples of Activities that Promote Motivation and Aspiration to Learn

\begin{tabular}{|c|c|c|}
\hline $\begin{array}{l}\text { Thinking } \\
\text { Skills }\end{array}$ & Explanation of Each Thinking Skills & Examples of Activities \\
\hline Enquiry & $\begin{array}{l}\text { ask relevant questions, to pose and define } \\
\text { problems, to plan what to do and how to } \\
\text { research, to predict outcomes and } \\
\text { anticipate responses, to test conclusions } \\
\text { and improve ideas }\end{array}$ & $\begin{array}{ll}\text { Mind-Mapping, } & \text { The } \\
\text { Complete Me, Jigsaw } & \end{array}$ \\
\hline $\begin{array}{l}\text { Information } \\
\text { Processing }\end{array}$ & $\begin{array}{l}\text { Locate and collect relevant information, } \\
\text { to sort, classify, sequence, compare, } \\
\text { contrast, and to analyze part/whole } \\
\text { relationships }\end{array}$ & $\begin{array}{l}\text { Sand Play, Round Robin, } \\
\text { Goldilocks and the } 3 \\
\text { Bears, Name of Key } \\
\text { Characters, Teacher, } \\
\text { Teacher, (writing a song), } \\
\text { Puppet Play }\end{array}$ \\
\hline Reasoning & $\begin{array}{l}\text { give reasons for opinions and actions, to } \\
\text { draw inferences and make judgments, to } \\
\text { use language to explain what they think, } \\
\text { and to make judgments and decisions } \\
\text { informed by reasons and evidence }\end{array}$ & $\begin{array}{l}\text { Story Telling (using } \\
\text { pictures), Re-telling of } \\
\text { Narrative, Treasure Hunt } \\
\text { (planning) }\end{array}$ \\
\hline Evaluation & $\begin{array}{l}\text { evaluate information, to judge the value } \\
\text { of what they read, hear and do, to develop } \\
\text { criteria for judging the value of their own } \\
\text { and others' work or ideas, and to have } \\
\text { confidence in their judgment }\end{array}$ & $\begin{array}{l}\text { B-Day } \quad \text { Graphs, } \\
\text { Everyone's Unique, Odd } \\
\text { One Out. }\end{array}$ \\
\hline
\end{tabular}


Cooperative learning strategies were also embedded in all activities, and this encouraged social interaction among the students. In cooperative learning, students learn in small groups, and help one another understand certain topics (Sharan, 2002; Slavin, 1995). Each activity was developed to challenge students' cognitive ability and to motivate them to learn more through fun learning activities. Some of the activities were; story-telling, mind mapping, puzzles, draw and tell, puppet play, and show and tell (as shown in Table 1.. Students were also asked to discuss and share their aspiration, hope and goals in life with peers and facilitators during their meetings. They were also taught time management, and expose to motivational discussion, to help students develop academic and life goals, study skills, and preparation for examination. The programs were conducted at the students' respective schools twice a month and each session lasted for five hours. After the program, students were given assignments to be completed and discussed during the next meeting.

\section{METHODOLOGY}

The research used a pre-post quasi experimental with control group design. The researchers collected the data three times over the period of three years. Thirty facilitators (22 males, 8 females) were trained for three days by the researchers to coordinate the activities with the students. The facilitators were employees of the oil company, and majority has no teaching background. The facilitators received teaching materials consisted of three modules (each represent one tier of the learning process). The facilitators' role was to facilitate the learning activities for the 10,11 and 12 years old students using the FLEP modules. Examples of one of the activity are shown in Table 2.

\section{Table 2. Example of the FLEP Activity}

\section{Promoting Enquiry Skills: Level 4 (10 years old)}

Activity: Mind-Mapping ((How to bake my favorite cookies)

Teaching time: 40 minutes

Objectives

At the end of the activity, students would be able to:

- plan what to do and how to research about baking a chocolate chip cookie

Steps for the Activity:

- Facilitator asks students to form small groups

- Facilitator gives students the material provided for the activity.

- Facilitator tell students:

- "If we want to bake a chocolate chip cookie, what shall we do?"

- As each major idea or theme emerges from your brain draw a line radiating from the cookie

- Write the name of the major idea above each line

- (Tell students to think out loud, and quickly put the idea on the paper)

- Facilitator ask students to present their Mind map to the group members

Alternative Activity

- For variation, you can ask the students to do the mind map on a butcher paper or drawing paper

- In order to do this, ask the students to draw picture of the chocolate chip cookie at the center of the butcher paper

- Then ask students to draw a line (for each idea) radiating from the cookie

- To make the lesson more interesting, facilitator may want to bring along to the class some real chocolate chip cookies

Teaching materials

- Butcher paper (Optional)

- Crayons

- Drawing paper 
Procedures to conduct the research are as follows:

1. Schools were selected based on the following criteria: the oil company has a refinery center within the locality of the school (this criterion is chosen because the FLEP program is part of the CSR activity of the oil company)

2. A letter was send to the local district education office informing of the study and the schools that will be involved

3. Three days weekend training was conducted by the researchers for the facilitators who are also employees of the oil company using similar FLEP model that was used for the students

4. Students were selected based on the academic performance criteria. Selected students were those who constantly fail or have high absenteeism percentage

5. The students were randomly assigned into experimental and control group and were given a pre-test to examine their motivation and aspiration to learn

6. Students in the experiment group were asked to come to the school twice a month (every alternate week) to participate in the FLEP program facilitated by the facilitators from the oil company

Students were given take home assignment after each session

The first posttest was given at the end of the $12^{\text {th }}$ months

This indicates the first cycle of the FLEP program for the 10 year old students

The students then moved to the second cycle of the program (by now they are 11 years old), and then to the third and last cycle when they were 12

Each cycle will end with a post-test. In total, data were taken three times throughout the study

The samples are 596 students from six primary schools located in very rural areas. These students were identified as low-achievers by their respective schools. The students were coming from low socioeconomic income families (parents work either as farmers, fishermen, rubbertappers, general labours, or factory workers), with average monthly earnings of less than 900 Malaysian Ringgit. The students were also identified as at-risk in terms of their tendency to fail or did poorly in their examination. Attrition rate among these students were also high given the fact that the students live in a very rural areas where educational resources are very limited and the interest in education among the parents were very low. Within each school, 50 students were selected for the experimental group and 50 for the control group. The students were randomly assigned. For the experimental group, the students were divided into small groups of 25 per class. Each class was handled by two to three trained facilitators. No drop out was observed from three schools throughout the program, but one student drop out from each of the other schools. Total number of students who completed the program is 297 , while the control groups remain at 300 until the program was completed.

The study used a set of the questionnaire developed on a three-point Likert scale. The questionnaire has 26 items that measured motivation and aspiration to learn. The researchers collected the data over a three years period. A pilot study aimed to examine the reliability of the questionnaire was conducted on year four students. The original pilot tested questionnaire has 34 items, while the final edition has 26 items. The Alpha Cronbach values are 0.87 (for motivation to learn) and 0.93 (for aspiration to learn) respectively. Data collected from the three years were then analyzed using descriptive (Mean, SD) and inferential statistic (independent sample t-test, and paired sample t-test). Example of items that measure motivation to learn are: a) I know when to study; b) I want to be successful in school; c) I will study very hard to score better grade in school; and d) I will ask questions when I do not understand what is being taught. Example of items that measure aspiration to learn are: a) I study because it will help me get a better job; b) I pay attention 
in class because that will help me get better grades; c) I study very hard because I want to be the top of my class; and d) I want to be a someone important in the future.

\section{RESULTS AND DISCUSSION}

Students' motivation and aspiration to learn were compared during the first, second and third year. Prior to intervention, the students were weak in both areas, and the mean difference for motivation and aspiration for experimental and control groups were extremely small $(\mathrm{MD}=0.08$ and $\mathrm{MD}=0.50)$. However, mean for motivation for the experimental group increased by 9.55 points while mean for aspiration to learn increased by 11.78 points in the third year (please refer to Table 3).

Table 3. Mean, SD and SEM (Experimental and Control Groups)

\begin{tabular}{lllcccc}
\hline & & GROUPS & N & Mean & SD & SEM \\
\hline \multirow{3}{*}{ Year1 } & Motivation & Experimental & 296.00 & 24.64 & 4.62 & 0.27 \\
& & Control & 300.00 & 24.72 & 4.58 & 0.26 \\
& \multirow{2}{*}{ Aspiration } & Experimental & 293.00 & 17.83 & 3.61 & 0.21 \\
& & Control & 297.00 & 17.33 & 3.62 & 0.21 \\
\hline \multirow{3}{*}{ Year 2 } & \multirow{2}{*}{ Motivation } & Experimental & 296.00 & 28.38 & 4.60 & 0.27 \\
& & Control & 300.00 & 27.19 & 4.51 & 0.26 \\
& \multirow{2}{*}{ Aspiration } & Experimental & 294.00 & 21.08 & 3.61 & 0.21 \\
& & Control & 297.00 & 16.86 & 3.71 & 0.22 \\
\hline \multirow{3}{*}{ Year 3 } & \multirow{2}{*}{ Motivation } & Experimental & 296.00 & 34.19 & 4.60 & 0.27 \\
& & Control & 300.00 & 29.56 & 5.43 & 0.31 \\
& \multirow{2}{*}{ Aspiration } & Experimental & 294.00 & 29.61 & 4.35 & 0.25 \\
& & Control & 297.00 & 20.83 & 3.69 & 0.21 \\
\hline
\end{tabular}

Table 4 shows the $\mathrm{p}$ value for motivation in Year 1 is $0.82(\mathrm{p}>0.05)$, and the $\mathrm{p}$ value for aspiration is $0.10(\mathrm{p}>0.05)$. In Year 2, the mean values increased for both experimental and control group. However, for both variables, the increased in the experimental group is more than the increased found in the control group. For both groups, the difference in mean for motivation and aspiration is significant $(p<0.05)$. Means for both variables increased further in 2008 , and the mean difference is significant $(\mathrm{p}<0.05)($ Table 3$)$.

Table 4. Independent Samples t-Test

\begin{tabular}{llrrrrr}
\hline & & \multicolumn{1}{c}{ T } & Df & p & MD & SED \\
\hline Year 1 & Motivation & -0.23 & 594.00 & 0.82 & -0.08 & 0.38 \\
& Aspiration & 1.66 & 588.00 & 0.10 & 0.49 & 0.30 \\
Year 2 & Motivation & 3.18 & 594.00 & 0.01 & 1.19 & 0.37 \\
& Aspiration & 14.04 & 589.00 & 0.00 & 4.23 & 0.30 \\
& & & & & & \\
Year 3 & Motivation & 11.20 & 594.00 & 0.00 & 4.63 & 0.41 \\
& Aspiration & 26.47 & 589.00 & 0.00 & 8.78 & 0.33 \\
\hline
\end{tabular}

Data was also analysed using paired samples statistics for the experimental group. Prior to intervention, comparison made between male and female students shows that both groups differ in their motivation and aspiration to learn. Mean for motivation among the male students is 24.79 $(\mathrm{SD}=4.66, \mathrm{SEM}=0.28)$, and their mean for aspiration to learn is $17.69(\mathrm{SD}=3.61, \mathrm{SEM}=0.27)$. Similarly, mean value for motivation for the female student is 24.57 ( $\mathrm{SD}=4.54$, SEM=0.26), and mean value for aspiration to learn is $17.47(\mathrm{SD}=3.62, \mathrm{SEM}=0.21)$. However, the mean values 
increased in year 2 and year 3 . For the male students, mean values for motivation in year 2 is 28.01 ( $\mathrm{SD}=4.51, \mathrm{SEM}=0.27)$ and for aspiration to learn is $19.18(\mathrm{SD}=4.14, \mathrm{SEM}=0.25)$. For the female students, the mean value for motivation is 27.57 ( $\mathrm{SD}=4.65, \mathrm{SEM}=0.26)$, and for aspiration to learn, the mean value is $18.76(\mathrm{SD}=4.30, \mathrm{SEM}=0.25)$.

Table 5 shows the correlations between the paired years (Year 1 and 2, Year 1 and 3, and Year 2 and 3). There are strong correlations between the years for both male and female students on both motivation and aspiration to learn. All $\mathrm{p}$ values are less than 0.05 . This indicates that students who did well in year 1 also did well in year 2 and year 3 .

Table 5. Paired Sample Correlation for Experimental Group across Gender

\begin{tabular}{llccc} 
Gender & Group & $\mathbf{N}$ & $\mathbf{r}$ & $\mathbf{p}$ \\
\hline Male & Pair 1 & 285.00 & 0.94 & $0.00^{*}$ \\
& Pair 2 & 285.00 & 0.87 & $0.00^{*}$ \\
& Pair 3 & 285.00 & 0.86 & $0.00^{*}$ \\
& Pair 4 & 285.00 & 0.68 & $0.03^{*}$ \\
& Pair 5 & 285.00 & 0.85 & $0.00^{*}$ \\
& Pair 6 & 285.00 & 0.87 & $0.00^{*}$ \\
\hline Female & Pair 1 & 311.00 & 0.98 & $0.00^{*}$ \\
& Pair 2 & 305.00 & 0.82 & $0.00^{*}$ \\
& Pair 3 & 311.00 & 0.79 & $0.01^{*}$ \\
& Pair 4 & 305.00 & 0.54 & $0.04^{*}$ \\
& Pair 5 & 311.00 & 0.90 & $0.00^{*}$ \\
& Pair 6 & 306.00 & 0.88 & $0.00^{*}$ \\
\hline
\end{tabular}

*Sig. at 0.05

The analysis also shows that for Year 1, and 2, the mean for motivation and aspiration to learn for both groups is significant. However, there was an increase in mean for both variables during the third year. For male students, the mean for motivation for the third year is 32.83 $(\mathrm{SD}=5.29, \mathrm{SEM}=0.31)$ and the mean value for aspiration to learn is $24.69(\mathrm{SD}=5.45, \mathrm{SEM}=0.32)$. For the female students, the mean value for motivation is 24.57 ( $\mathrm{SD}=4.54, \mathrm{SEM}=0.26$ ), and for aspiration to learn, the mean value is $25.66(\mathrm{SD}=6.38, \mathrm{SEM}=0.37)$. When comparison between years (Year 1 and 2, Year 2 and 3, and Year 1 and 3) was made for male students, the results show that the paired sample means for motivation increases from 3.22, to 5.51 to 8.04. For the female students, the paired sample means for motivation increases from 3.00 to 3.40 to 6.39. For aspiration, the male students paired sample means are 1.49, 5.51 and 7.00, while for the female students, the paired sample means are 1.29, 6.92 and 8.91. Since all $\mathrm{p}$ values are less than 0.05, therefore, the paired sample means are all significant (Table 6). 
Table 6: Paired Sample Test for Experimental Group across Gender

Paired

Differences

\begin{tabular}{lllllclc}
\hline & & Mean & SD & SEM & t & df & P \\
\hline Male & Pair 1 & -3.22 & 1.64 & 0.10 & -33.17 & 284 & $0.00^{*}$ \\
& Pair 2 & -1.49 & 2.03 & 0.12 & -12.37 & 284 & $0.00^{*}$ \\
& Pair 3 & -8.04 & 2.7 & 0.16 & -49.71 & 284 & $0.00^{*}$ \\
& Pair 4 & -7.00 & 4.00 & 0.24 & -29.57 & 284 & $0.00^{*}$ \\
& Pair 5 & -4.82 & 2.83 & 0.17 & -28.73 & 284 & $0.00^{*}$ \\
& Pair 6 & -5.51 & 2.73 & 0.16 & -34.05 & 284 & $0.00^{*}$ \\
\hline Female & Pair 1 & -3.00 & 1.00 & 0.06 & -52.76 & 310.00 & $0.00^{*}$ \\
& Pair 2 & -1.29 & 2.47 & 0.14 & -9.13 & 304.00 & $0.00^{*}$ \\
& Pair 3 & -6.39 & 3.47 & 0.20 & -32.51 & 310.00 & $0.00^{*}$ \\
& Pair 4 & -8.19 & 5.38 & 0.31 & -26.59 & 304.00 & $0.00^{*}$ \\
& Pair 5 & -3.40 & 2.49 & 0.14 & -24.05 & 310.00 & $0.00^{*}$ \\
& Pair 6 & -6.92 & 3.33 & 0.19 & -36.37 & 305.00 & $0.00^{*}$ \\
\hline
\end{tabular}

$*$ Sig. at 0.05

This study was able to shed some light into the low-achievers' motivation and aspiration to learn, and the effectiveness of the FLEP program in increasing their motivation and aspiration to learn. Prior to the FLEP program, the students had low motivation and aspiration to learn. Bearing in mind that these students were identified as "GALUS", a concept used to describe lowachieving students whose academic performance is inconsistent across academic years, they have many disadvantages that might impede success in their academic work. Almost all students who participated in this study came from rural areas and had families from low-income group. Many lack role model to emulate in academic success. Their parent and family members were mostly farmers, rubber-tappers, and fishermen. In tandem, many did not have the opportunity to have extended help in their academic work, as experienced by middle or higher-income group students. They rely solely on the limited teaching and learning from the school. They were also not exposed to multiple learning strategies aside from the strategies introduced by their teachers. When these students were not given the opportunity to receive effective learning strategies, they would not be able to engage fully in the learning experience (Cheung \& Chan, 2008; Harper \& Maheady, 2007).

After the first and second year in the FLEP program, the students' mean for motivation and aspiration to learn increased by more than 30 percent. The students participated in both academic and non-academic activities in the program. With regards to the non-academic activities, the students shared, collaborated, and present work that represent their motivation and aspirations to learn. They learned mathematics and science through collaborative learning, and their cognitive abilities were challenged constantly. The students were also able to interact with their role model cum facilitators. These role models were the real-life model that the students could emulate. The collaboration increased the students' motivation and aspiration to do better in their academic work, and inevitably, promote positive self-beliefs about academic achievement. This finding supported Pajares et al. (2000) study on the relationship between motivation, achievement goals and self-beliefs in writing and science among middle school students. Their study shows a strong correlation between the variables and students who belief that they could do certain tasks felt motivated to try and complete the task. They also developed better achievement goals and strive to reach that goals. They developed intrinsic motivation to continue learning on their own. A study conducted by Pintrich and De Groot (1990) also shows similar 
results. In addition, their study shows that students, who were highly motivated, aspire to do better. They could regulate their behaviors to achieve better academic performance. Studies have found that students who were more persistent at tackling difficult or uninteresting academic tasks always belief that they were more capable in completing the task than their counterpart (Pajares et al., 2000; Harper \& Maheady, 2007; Schicka \& Phillipson, 2009). In other words, they found learning to be achievable activities.

Prior to intervention, the data also shows that mean for motivation and aspiration to learn are almost the same for both male and female students. This shows that both groups are homogeneous in terms of motivation and aspiration to learn. After the first-year intervention, the mean increased for both groups. This trend continued even after the second year intervention. The correlation values are highly significant, which suggest that students who have high mean for both motivation and aspiration to learn in year 1 also have high means for both variables in year 2 and 3. The paired sample test conducted on the experimental group shows that the increase in mean is almost the same for both male and female students. It is surprising to note that, in general, the male students' mean across the years are slightly better than the female students. However, due to limitation in the report writing, statistical analysis to examine if the mean difference is significant was not conducted. Contrary to evidence provided by previous research (which suggest that female students fare better than male students in many areas) findings from this study shows that given the opportunity to learn, male students can perform, if not better, at par with their female counterparts. When both groups were given similar activities that motivate and inspire them to learn, they were able to develop their learning potential to the fullest. Furthermore, while there were female facilitators involved in the FLEP program, many of the facilitators were male engineers working at the refinery or sit e office. They interacted with the students for three years, working as a group in a buddy system. This probably put the male students at an advantage because they were able to develop strong bonding, interact freely with the male facilitators, and regards the facilitators as their role models.

\section{CONCLUSION}

In conclusion, low-achieving students can develop motivation and aspiration to learn when given the opportunity, the effective strategies, and the environment that promote positive learning experiences. As mentioned earlier motivation to learn is not related to general intelligence, but more so to variable related to aspiration to learn (Schicka \& Phillipson (2009). Therefore, regardless of academic performance, and intelligence, these students can be motivated to learn and improve their academic performance. Gebhard (1948) posits that, one will aspire to start or finish a given task when placed in a growth promoting learning environment. This aspiration will increase one's motivation to learn. Findings from this study have implication towards the formal and informal teaching and learning process. Teachers need to look seriously on ways to immerse students in the learning process, and one of the ways that has been proven effective in this study is the fun learning experience. Learning that involves memorizing content will only promote rote learners that can be very taxing on students. Inevitably, students will lose interest in the learning process. Learning needs to implicate play and play need to be fun for students to stay focus on the learning process. Future research should look into ways to embed FLEP into learning of other subject areas. It would also be interesting to examine effectiveness of FLEP in promoting thinking skills and collaborative learning that was used as the basis of the activities in this study. This study is a three-year longitudinal experimental pre-post test with control group. To bring meanings to the idea of learning motivation and aspiration to learn, future researchers could also interview and observe the students behaviors while participating in the FLEP program. This will lead to better understanding of the students' learning motivation and aspiration to learn. 


\section{REFERENCES}

Alderman, M. K. (1990). Motivation for at-risk students. Educational Leadership, 48(1), 27-30.

Brophy, J., \& Good, T. (1988). Teachers' behavior and students' achievement. Educational Psychologist, 23(3), 235-286.

Cheung, C.S. \& Chang, C.M. (2008). Relation of perceived maternal parenting styles, practices and learning motivation to academic competence in Chinese children. Merrill-Palmer Quarterly, 54(1), 1-22.

DeBacker, T. K., \& Nelson, R. M. (1999). Variations on an expectancy-value model of motivation in science. Contemporary Educational Psychology, 24(2), 71-94.

Eisenberg, N., Martin, C. L., \& Fabes, R. A. (1996). Gender development and gender effects. In D. C. Berliner \& R. C. Calfee (Eds.), Handbook of Educational Psychology. New York: Simon \& Schuster/Macmillan

Elliott, J. G., Hufton, N., Illushin, L., \& Fraser, L. (2001). Motivation in the Junior Years: International perspectives on children's attitudes, expectations and behaviour and their relationship to educational achievement. Oxford Review of Education, 27(1), 37-68.

Frank, J. D. (1935). Individual differences in certain aspects of the level of aspiration. The American Journal of Psychology, 47(1), 119-128.

Ganci, S. A., Dantas, A. M., William, D.A. \& Kemm, R.E. (2009). Promoting student-centered active learning in lectures with a personal response system. Advance Physiological Education, 33(1), 60-71.

Gebhard, M. E. (1948). The effect of success and failure upon the attractiveness of activities as a function of experience, expectation, and need. Journal of Experimental Psychology, 11(4), 3749.

Hargis, C. H. (2006). Teaching low achieving and disadvantage students. Springfield: Charles C. Thomas Publishers.

Harper, G. F. \& Maheady, L. (2007). Peer-mediated teaching and students with learning disabilities. Intervention in Schools and Clinics. 43(2), 101-107.

Henal Shah (2007). Psychological aspects of academic failure among children. Exceptional Children, 52(1), 535-542.

Kagan, S. (1992). Cooperative Learning $\left(7^{\text {th }}\right.$ Ed). San Juan: Kapistrano, CA Resources for Teachers.

Kajamies, A., Vauras, M., Kinnunen, R. (2010). Instructing low-achievers in mathematical word problem solving. Scandinavian Journal of Educational Research, 54(4), 335-355.

Lau, K. L., \& Chan, D. W. (2001). Motivational characteristics of underachievers in Hong Kong. Educational Psychology, 21(4), 417-430.

Maheady, L., Harper, G. E., \& Mallette, B. (2000). Peer-mediated interventions and students with mild disabilities. Remedial and Special Education, 22(1), 12-55.

Pajares, F. (2003). Self-efficacy beliefs, motivation, and achievement in writing: A review of the literature. Reading and Writing Quarterly, 19(2), 139-158.

Pajares, F., \& Valiante, G. (2001). Gender differences in writing motivation and achievement of middle school students: A function of gender orientation? Contemporary Educational Psychology, 26(3), 366-381. 
Pajares, F., Britner, S. L., \& Valiante, G. (2000). Relation between achievement goals and selfbeliefs of middle school students in writing and science. Contemporary Educational Psychology, 25(4), 406-422.

Pajares, F., \& Graham, L. (1999). Self-efficacy, motivation constructs, and Mathematics performance of entering middle school students. Contemporary Educational Psychology, 24(2), 124-139

Pajares, F., Miller, M. D., \& Johnson, M. J. (1999). Gender differences in writing self-beliefs of elementary school students. Journal of Educational Psychology. 91(1), 50-61.

Perkins-Gough, D. (2006). Accelerating the learning of low achievers. Educational Leadership, 63(5), 88-89.

Pintrich, P. R. (1989). The dynamic interplay of student motivation and cognition in the college classroom. In Ames, C. and Maehr, M. (Eds), Advances in motivation and achievement: Vol. 6. Motivation enhancing environments. Greenwich, CT: JAI Press.

Pintrich, P. R., \& De Groot, E. V. (1990). Motivational and self-regulated learning components of classroom academic performance. Journal of Educational Psychology, 82(1), 33-40.

Secretan, L. K. (2005). Inspiring people to their greatness. Leader to Leader, 36(1), 11-14.

Schick, H., \& Phillipson, S. N. (2009). Learning motivation and performance excellence in adolescents with high intellectual potential: what really matters? High Ability Studies, 20(1), $15-37$.

Slavin, R. E. (1995). Cooperative leaming: Theory, Research, and Practice (2 ${ }^{\text {nd }}$ ed.). Boston: Allyn \& Bacon.

Rogers, C. (1980). A way of being. Boston, MA: Houghton Mifflin.

Tan, I. G. C., Sharan, S., \& Lee, C. K. E. (2007). Group investigation effects on achievement, motivation, and perceptions of students in Singapore, The Journal of Educational Research, 100(1), $142-154$.

Wong, B. Y. C., Butler, D. L., Ficzere, S. A., \& Kuperis, S. (1996). Teaching low achievers and students with learning disabilities to plan, write and revise opinion essays. Journal of Learning Disabilities, 29(2), 197-212. 